\title{
Abnormal subpopulations of peripheral blood lymphocytes are involved in Parkinson's disease
}

\author{
Congcong Sun ${ }^{1}$, Zhenxiang Zhao ${ }^{2}$, Wenfei Yu ${ }^{1}$, Mingshu Mo ${ }^{3}$, Chengyuan Song ${ }^{1}$, Youfeng $i^{4}$, Yiming Liu ${ }^{1}$ \\ ${ }^{1}$ Department of Neurology, Qilu Hospital of Shandong University, Jinan 250012, China; ${ }^{2}$ Department of Neurology, Henan Provincial People's \\ Hospital, People's Hospital of Zhengzhou University, Zhengzhou 450003, China; ${ }^{3}$ Department of Neurology, First Affiliated Hospital of Guangzhou \\ Medical University, Guangzhou 510120, China; ${ }^{4}$ Department of Neurology, Feicheng Mining Central Hospital, Feicheng 271600, China \\ Contributions: (I) Conception and design: C Sun, Y Liu; (II) Administrative support: None; (III) Provision of study materials or patients: C Sun, W \\ Yu, M Mo; (IV) Collection and assembly of data: Z Zhao, W Yu, M Mo, C Song; (V) Data analysis and interpretation: Z Zhao, C Song, Y Si; (VI) \\ Manuscript writing: All authors; (VII) Final approval of manuscript: All authors. \\ Correspondence to: Yiming Liu. Department of Neurology, Qilu Hospital of Shandong University, No. 107, Wenhua West Road, Jinan 250012, \\ China. Email: liuym@sdu.edu.cn.
}

Background: Abnormal immune responses are involved in the development of Parkinson's disease (PD), and also affect peripheral blood lymphocytes. The profile of lymphocyte subsets in peripheral blood and whether it is relevant to the clinical features of PD patients remains controversial.

Methods: To explore the role of peripheral blood lymphocytes (NK cells, B cells, CD ${ }^{+} \mathrm{T}$ cells, $\mathrm{CD}^{+} \mathrm{CD}^{+}$ $\mathrm{T}$ cells and $\mathrm{CD}^{+}{ }^{+} \mathrm{CD}^{+} \mathrm{T}$ cells) in the development of $\mathrm{PD}$, a case-control study including 127 patients and 148 healthy controls was conducted, and peripheral blood lymphocyte subpopulations of participants were analysed by a FACSCalibur flow cytometer.

Results: PD patients had a significantly higher percentage of NK cells and a lower percentage of CD $3^{+}$ $\mathrm{T}$ cells and $\mathrm{CD}^{+} \mathrm{CD}^{+} \mathrm{T}$ cells than controls $[16.4 \%$ (12.3\%) vs. $12.6 \%$ (6.2\%), 63.7\% (14.2\%) vs. 69.0\% (6.6\%), 33.1\% (13.1\%) vs. 38.9\% (7.6\%), $\mathrm{P}<0.05$, respectively]. Through a binary logistic regression model adjusted for gender and age, we found that those who were outside of the reference range of peripheral blood lymphocytes (NK cell, B cell, $\mathrm{CD}^{+} \mathrm{T}$ cell and $\mathrm{CD}^{+} \mathrm{CD}^{+} \mathrm{T}$ cell) had an increased risk of PD [odds ratio (OR): 2.3, 5.1, 3.1 and 4.1, $\mathrm{P}<0.05$, respectively]. Through a multivariable linear regression model adjusted for gender, age and levodopa equivalent daily dose, we found that deviation from the reference range of $\mathrm{CD}^{+} \mathrm{CD}^{+} \mathrm{T}$ cells (regression coefficient $=3.474, \mathrm{P}=0.015$ ), course of disease (regression coefficient $=0.411$, $\mathrm{P}=0.004$ ) and the Non-Motor Symptoms Scale (NMSS) scores (regression coefficient =0.553, P=5.92E-11) had a positive association with the Movement Disorders Society-Unified Parkinson's Disease Rating Scale (MDS-UPDRS)-III score (adjusted $\mathrm{R}^{2}=0.364, \mathrm{~F}=13.004$ ).

Conclusions: Abnormal peripheral blood lymphocyte subpopulations have clinical relevance for PD.

Keywords: Parkinson's disease (PD); peripheral lymphocyte subsets; reference range

Submitted Jul 17, 2019. Accepted for publication Oct 12, 2019.

doi: $10.21037 /$ atm.2019.10.105

View this article at: http://dx.doi.org/10.21037/atm.2019.10.105

\section{Introduction}

Parkinson's disease (PD) is the second most common neurodegenerative disorder in the elderly population (1). Patients suffer from bradykinesia, resting tremor, rigidity and a variety of non-motor symptoms. Most dopaminergic neurons have degenerated with Lewy body deposition before the typical movement disorders appear (2).

Alpha-synuclein ( $\alpha$-syn) is the main protein constituent of Lewy bodies, and this protein spreads from neuron to neuron similar to prion behaviour (3). Its fibrils have been shown to recruit peripheral immune cells in rat brain studies 
Table 1 Review of the percentage of peripheral blood lymphocyte subsets in patients with PD and healthy controls

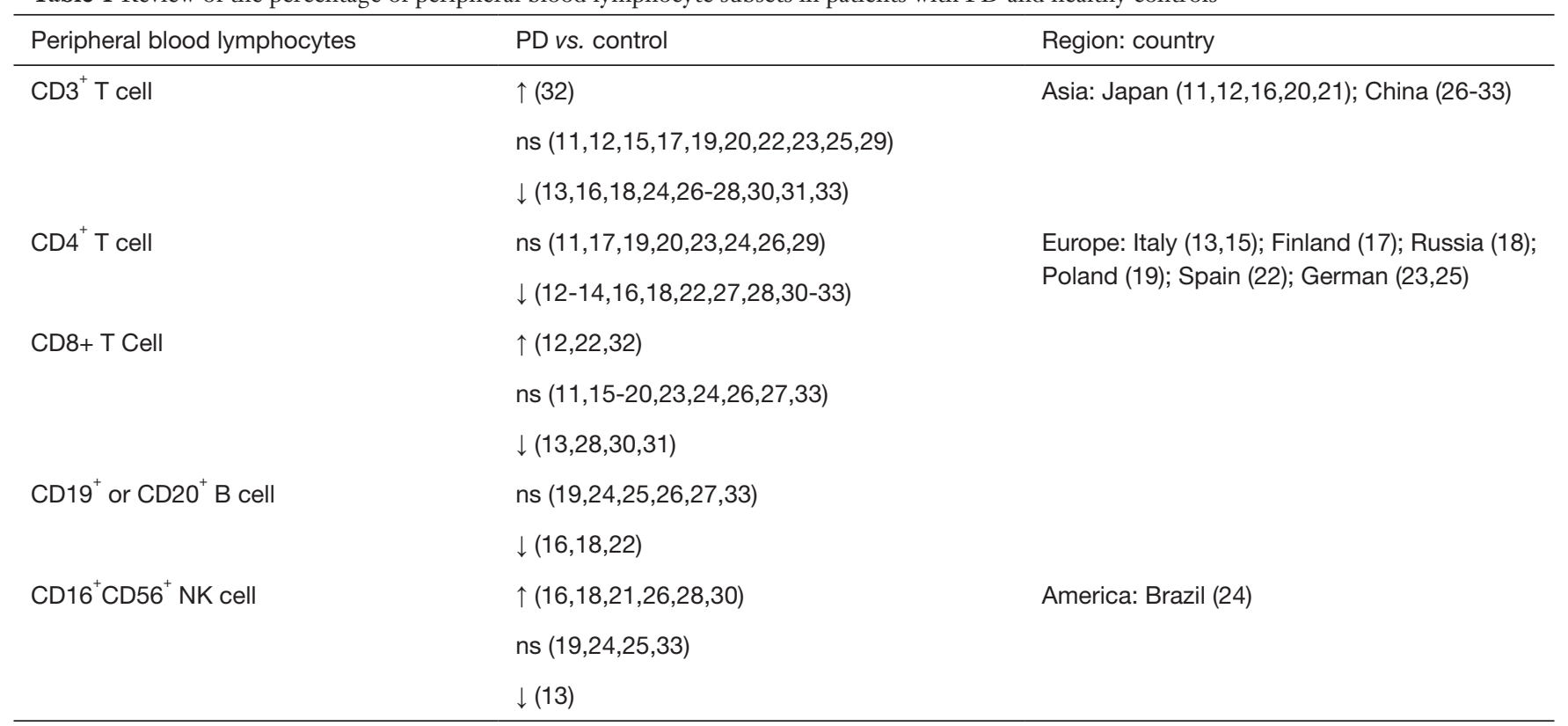

$\uparrow / \downarrow$ : compared to the healthy controls, the increase or decrease of the percentages of peripheral blood lymphocytes in patients with PD is statistically significant. ns, no statistical significance; PD, Parkinson's disease.

prior to neurodegeneration (4). Numerous post-mortem studies have documented that innate and adaptive immunity are involved in the progression of PD (5). A defined set of peptides derived from $\alpha$-syn, act as antigenic epitopes and drive helper and cytotoxic $\mathrm{T}$ cell responses in $\mathrm{PD}$ patients (6). Unlike B cells or natural killer cells, $\mathrm{CD}^{+}$and $\mathrm{CD}^{+} \mathrm{T}$ lymphocytes in the vicinity of blood vessels and dopaminergic neurons have been detected in post-mortem brain tissues $(7,8)$. Misfolded $\alpha$-syn is not only prevalent in the central nervous system, but can also be released into the extra neuronal space and can cross the blood-brain barrier (BBB) and alter peripheral leukocytes $(9,10)$.

Clinical studies conducted in the last 30 years have indicated that the percentage of NK cell, B cell and T cell subsets were altered in peripheral blood lymphocytes in PD patients (11-33). The level of these lymphocytes may be associated with the clinical features of $\mathrm{PD}$, such as age, course of disease (27), severity of illness $(16,29,33,34)$ and medication $(19,35)$. However, after reviewing these studies, we found that most of these case-control studies had relatively small sample sizes $(<50)$ and were widely heterogeneous (involving different regions, races, gender or age proportions, clinical features, medication, testing methods and statistical methods); thus no consistent results have yet been drawn (Table 1).
To obtain the profile of peripheral blood lymphocyte subsets in PD patients in the Chinese Han population and ascertain any possible associations between peripheral blood lymphocytes and clinical features of PD, we investigated the lymphocyte subset distribution in PD patients and healthy controls to characterize the differences. We also investigated the impact of these alterations on the disease's development.

\section{Methods}

\section{Participants}

A total of 127 sporadic PD patients and 148 healthy controls were enrolled in this study in Shandong Province, China (basic characterization shown in Table 2). All participants belonged to the Han Chinese population. All patients were diagnosed with clinically established PD or clinically probable PD according to the International Parkinson and Movement Disorder Society (MDS) Clinical Diagnostic Criteria (36) at the clinic of Qilu Hospital from 2017 to 2019. The Movement Disorders SocietyUnified Parkinson's Disease Rating Scale (MDS-UPDRS) and the Non-Motor Symptoms Scale (NMSS) were used to assess motor and non-motor symptoms in PD patients. The levodopa equivalent daily dose (LEDD) was estimated 
Table 2 Clinical features of PD patients and healthy controls

\begin{tabular}{lcccccc}
\hline Group & $\begin{array}{c}\text { Gender } \\
\text { (female/male) }\end{array}$ & $\begin{array}{c}\text { Age } \\
\text { (year) }\end{array}$ & $\begin{array}{c}\text { Course of disease } \\
\text { (year) }\end{array}$ & $\begin{array}{c}\text { MDS-UPDRS-III } \\
\text { (score) }\end{array}$ & $\begin{array}{c}\text { NMSS } \\
\text { (score) }\end{array}$ & $\begin{array}{c}\text { Equivalent dose } \\
\text { of L-dopa (mg) }\end{array}$ \\
\hline Control & $64 / 84$ & $60.3 \pm 13.4$ & - & - & - & - \\
PD & $52 / 75$ & $62.7 \pm 12.5$ & $4.4 \pm 4.1$ & $17.9 \pm 9.2$ & $10.1 \pm 7.4$ & $617.3 \pm 444.8$ \\
\hline
\end{tabular}

Gender is shown as the constituent ratio; other indexes are shown as the mean \pm SD. PD, Parkinson's disease; MDS-UPDRS, Movement Disorder Society-Sponsored Revision Unified Parkinson's Disease Rating Scale; NMSS, Non-Motor Symptom Scale; PD, Parkinson's disease; SD, standard deviation.

(clinical features are shown in Table 2). Healthy controls that were age- and gender-matched to patients were selected from the health examination centre. People with a history of alcoholism, cancer, autoimmune disease, or acute/ chronic inflammatory disorders were excluded.

Four millilitres of venous blood from participants was collected in tubes containing EDTA-K2 between 08:00 am and 10:00 am, then stored at room temperature and processed within three hours. Blood lymphocyte subsets were performed with a single-platform technique (37). A FACSCalibur flow cytometer (BD Biosciences, San Jose, CA, USA) was used to detect lymphocyte subsets with CD3 FITC/CD8 PE/CD45 PerCP/CD4 APC reagents and CD3 FITC/CD16 PE + CD56 PE/CD45 PerCP/ CD19 APC reagents (BD Biosciences). The percentage of $\mathrm{CD}^{+}{ }^{+} \mathrm{T}$ cells [reference value (Ref): $55-80 \%$ ], $\mathrm{CD}^{+} \mathrm{CD}^{+}$ T cells (Ref: $25-45 \%), \mathrm{CD}^{+}{ }^{+} \mathrm{CD} 8^{+} \mathrm{T}$ cells (Ref: $15-35 \%$ ), CD $19^{+} \mathrm{B}$ cells (Ref: 6-18\%) and $\mathrm{CD} 3^{-} \mathrm{CD} 16^{+} \mathrm{CD} 56^{+} \mathrm{NK}$ cells (Ref: $8-26 \%$ ) were calculated by the Cell Quest Pro software. To ensure high-quality consistent results, the flow cytometer instrument was calibrated daily, and the intensity of the antibody fluorescence was monitored weekly.

\section{Statistical analysis}

Data were expressed as the median (interquartile range). The Mann-Whitney test was conducted to compare the percentage of every type of peripheral blood lymphocyte between PD patients and healthy controls. The $\chi^{2}$ test was used to observe the number of PD patients and healthy controls inside/outside the reference range. Bonferroniadjusted $\mathrm{P}$ values $(\mathrm{Pc})$ were used to avoid alpha inflation.

Further analysis was performed in PD patients. PD patients were divided into different subgroups according to whether certain lymphocyte subset was inside or outside the reference range of NK cells, B cells, $\mathrm{CD}^{+} \mathrm{T}$ cells,

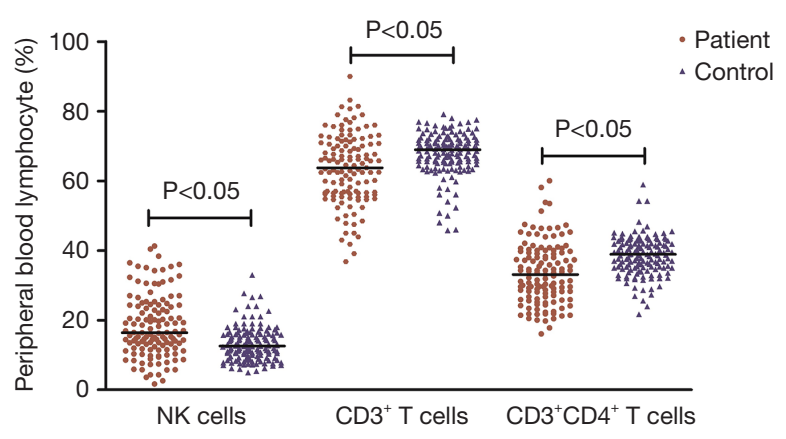

Figure 1 Difference in the percentage of peripheral lymphocyte subsets between PD (Parkinson's disease) patients and healthy controls. Data are presented as the median in the scatter plot and are compared with a nonparametric test. PD, Parkinson's disease.

$\mathrm{CD}^{+}{ }^{+} \mathrm{CD} 4^{+} \mathrm{T}$ cells or $\mathrm{CD} 3^{+} \mathrm{CD} 8^{+} \mathrm{T}$ cells. The clinical features of patients between the two subgroups in every peripheral blood lymphocyte subset were compared by the Mann-Whitney test. SPSS 12.0 software (Chicago, IL, USA) was used for the statistical analyses. $\mathrm{P}<0.05$ or $\mathrm{Pc}<0.01$ was regarded as statistically significant.

\section{Results}

\section{Differences in peripheral blood lymphocytes between PD patients and bealthy controls}

The percentage of NK cells in PD patients was significantly higher than that in healthy controls $[16.4 \%(12.3 \%)$ vs. $12.6 \%$ (6.2\%), $\mathrm{P}<0.05$, Figure 1]. The percentage of $\mathrm{CD}^{+} \mathrm{T}$ cells and $\mathrm{CD}^{+}{ }^{+} \mathrm{CD} 4^{+} \mathrm{T}$ cells in $\mathrm{PD}$ patients was significantly lower than that in healthy controls $[63.7 \%$ (14.2\%) vs. 69.0\% (6.6\%), 33.1\% (13.1\%) vs. $38.9 \%$ (7.6\%), $\mathrm{P}<0.05$, respectively, Figure 1]. No obvious differences in $\mathrm{CD}^{+} \mathrm{CD}^{+} \mathrm{T}$ cells and $\mathrm{CD} 19^{+} \mathrm{B}$ cells were detected between the PD and control groups $[25.9 \%(11.1 \%) v s$. $25.7 \%$ (7.6\%); $11.3 \%$ (7.6\%) vs. $11.5 \%$ (6.2\%), $\mathrm{P}>0.05]$. 
Table 3 Constituent ratio (inside/outside normal range) of peripheral blood lymphocytes

\begin{tabular}{lccccc}
\hline Group/indicator & NK & CD19 $^{+} \mathrm{B}$ & CD3 $^{+}$T & CD3 $^{+}$CD4 $^{+} \mathrm{T}$ & CD3 $^{+} \mathrm{CD}^{+} \mathrm{T}^{-}$ \\
\hline PD & $91 / 36$ & $94 / 33$ & $100 / 27$ & $92 / 35$ & $102 / 25$ \\
Control & $131 / 17$ & $139 / 9$ & $141 / 7$ & $135 / 13$ & $138 / 10$ \\
Pc value & $2.05 \mathrm{E}-3$ & $2.39 \mathrm{E}-5$ & $1.70 \mathrm{E}-4$ & $2.17 \mathrm{E}-4$ & $5.0 \mathrm{E}-3$ \\
\hline
\end{tabular}

The number of people inside/outside the normal range of indicators is shown in the cells. The $\chi^{2}$ test is used to compare the differences. Bonferroni adjusted Pc values $<0.01$ are regarded as statistically significant. PD, Parkinson's disease; Pc, Bonferroni-adjusted P value.

\section{Deviation from the reference range of peripheral blood lymphocytes is associated with an increased risk of PD}

During the study, we found that deviations in the percentage of peripheral blood lymphocytes away from the reference range seemed to be more common in $\mathrm{PD}$ patients. Through $\chi^{2}$ test and Bonferroni-adjusted Pc values, we found that compared with healthy controls, PD patients showed remarkable changes in the constituent ratio (inside/outside reference range) in five peripheral blood lymphocytes. The number of people with each lymphocyte subset deviating from the normal range in the $\mathrm{PD}$ group was clearly higher than that in the control group $\left(\mathrm{Pc}_{\mathrm{c}}<0.01\right.$, Table 3).

To explore the association between the phenomenon of peripheral blood lymphocytes deviating from the reference range and the occurrence of $\mathrm{PD}$, we conducted a binary logistic regression model including gender and age and whether NK cells, B cells, $\mathrm{CD}^{+}{ }^{+} \mathrm{T}$ cells, $\mathrm{CD}^{+} \mathrm{CD}^{+}{ }^{+} \mathrm{T}$ cells and $\mathrm{CD}^{+}{ }^{+} \mathrm{CD} 8^{+} \mathrm{T}$ cells were inside or outside the reference range. After adjusting for gender and age, we found that people with $\mathrm{NK}$ cells, B cells, $\mathrm{CD}^{+}{ }^{+} \mathrm{T}$ cells or $\mathrm{CD}^{+} \mathrm{CD}^{+} \mathrm{T}$ cells deviating from the reference range had an increased risk of PD [odds ratio (OR) (95\% CI): 2.3 (1.1-4.5), 5.1 (2.3-11.6), 3.1 (1.2-8. 0), 4.1 (1.8-9.1), $\mathrm{P}<0.05$, respectively].

\section{Associations between the phenomenon of peripheral blood lymphocytes deviating from the reference range and clinical features in PD}

To further explore the association between the phenomenon of peripheral blood lymphocytes deviating from the reference range and clinical features of patients with $\mathrm{PD}$, we divided the patients into two subgroups according to the percentage that were inside or outside the reference range of NK cells, B cells, $\mathrm{CD}^{+}{ }^{+} \mathrm{T}$ cells, $\mathrm{CD} 3^{+} \mathrm{CD} 4^{+} \mathrm{T}$ cells or $\mathrm{CD}^{+} \mathrm{CD} 8^{+} \mathrm{T}$ cells respectively. Then we compared the differences in clinical features (age, course of disease, MDSUPDRS-III scores, NMSS scores and LEDD) between the two subgroups of every lymphocyte subset using the MannWhitney test. We found that patients who had $\mathrm{CD}^{+} \mathrm{CD}^{+}$ $T$ cells deviating from the reference range had significantly higher MDS-UPDRS-III scores than patients with normal indicators [14.0 (10.0) vs. 10.5 (8.0), $\mathrm{P}=0.012]$. Patients with $\mathrm{B}$ cells and $\mathrm{CD} 3{ }^{+} \mathrm{CD}^{+} \mathrm{T}$ cells deviating from the reference range had significantly lower NMSS scores than patients with normal indicators [6.0 (7.0) vs. 9.0 (10.0), $\mathrm{P}=0.022 ; 6.0$ (7.0) vs. 9.0 (10.0), $\mathrm{P}=0.013$ ]. Through multivariable linear regression models adjusted for gender, age and LEDD, we found that deviation from the reference range of $\mathrm{CD}^{+} \mathrm{CD}^{+}$ $\mathrm{T}$ (regression coefficient $=3.474, \mathrm{P}=0.015$ ), course of disease (regression coefficient $=0.411, \mathrm{P}=0.004$ ) and NMSS scores (regression coefficient $=0.553, \mathrm{P}=5.92 \mathrm{E}-11$ ) all had a positive association with the MDS-UPDRS-III score (adjusted $\mathrm{R}^{2}=0.364, \mathrm{~F}=13.004$ ).

\section{Discussion}

The main aim of our study was to profile subsets of peripheral blood lymphocytes in PD patients in the Chinese Han population. PD patients showed a remarkable increase in NK cells and a decrease in $\mathrm{CD}^{+}$lymphocyte and $\mathrm{CD}^{+} \mathrm{CD}^{+}$lymphocyte subsets compared with those of healthy controls. Deviation from the normal range of peripheral blood lymphocytes was common in PD patients and was associated with an increased risk of PD. Deviation from the normal range of $\mathrm{CD}^{+} \mathrm{CD}^{+} \mathrm{T}$ cells was positively correlated with the severity of motor dysfunction in PD patients, as assessed by the MDS-UPDRS-III score.

Alterations in the population of blood lymphocytes in patients with PD have been widely studied. Ageing is known as a high-risk factor for the development of PD (38). Meanwhile, the ageing of the immune system is also commonly observed in the peripheral lymphocytes of healthy controls (39). Based on this finding, we formed a 
healthy control group matched to patients on race, region, gender and age rather than reference range. Compared with healthy controls, an increased percentage of NK cells and a decreased percentage of $\mathrm{CD}^{+}$and $\mathrm{CD} 3^{+} \mathrm{CD}^{+}$lymphocyte subsets were found in PD patients. This result is consistent with the result of a previous meta-analysis, involving 943 cases of PD (40).

Few studies have shown results concerning deviation from the reference range of peripheral blood lymphocytes. The establishment of the reference range depends on various factors, including race, region, gender, age, peripheral blood collection time and the technique $(37,41-44)$. With this in mind, our reference range is similar to that of a study which looked at the same population in our region (45). We found that the percentage of PD patients that deviated from the normal range of peripheral lymphocytes was significantly higher than that of healthy controls. This finding was true for all five indicators, including $\mathrm{NK}$ cells, B cells, $\mathrm{CD} 3^{+} \mathrm{T}$ cells, $\mathrm{CD} 3^{+} \mathrm{CD} 4^{+} \mathrm{T}$ cells and $\mathrm{CD}^{+} \mathrm{CD}^{+} \mathrm{T}$ cells. This result suggested that alterations in peripheral immunity existed in PD patients. Most importantly, the phenomenon of peripheral blood lymphocytes deviating from the reference range contributed to an increased risk of $\mathrm{PD}$, which further indicated that alterations in peripheral lymphocytes were involved in the pathogenesis of PD. Possible mechanisms leading to alterations in peripheral blood lymphocytes in PD patients include: (I) abnormal $\alpha$-syn accumulation in both the central nervous system and the periphery (46). In addition, $\alpha$-syn peptides can act as antigenic epitopes to drive NK cell, $\mathrm{CD}^{+} \mathrm{T}$ cell and $\mathrm{CD} 8^{+} \mathrm{T}$ cell responses in patients with $\mathrm{PD}(6,13), \alpha$-syn also induces apoptosis by altered expression in human peripheral lymphocytes in PD (47). (II) It was found that dopamine receptors (DR) could be expressed in subsets of human leukocytes, and dysfunctional peripheral dopamine signaling might be correlated with the dysfunctional immune responses in PD (48-50). (III) Recent studies highlight that the CNS is no longer an immunoprivileged site (51). NK cells, B cells and T cell subsets are present in brain boundaries, mostly located in the meninges and the blood-cerebrospinal fluid barrier (BCSFB). These cells may serve as communication bridges to and from the brain (52). (IV) Innate immunity and adaptive immunity accomplish their functions together, and each lymphocyte subpopulation usually interacts with other subsets through cytokines (53).

NK cells act as a first-line defense, which might be strengthened by environmental factors, such as HSV-I infection, gastrointestinal microbiota and be accompanied by higher $\alpha-S N$ expression levels in PD blood $(13,47,54)$. NK cells promote the differentiation of activated $\mathrm{CD}^{+}$ cells into Th1 and act as a go-between in innate and adaptive immune systems (16). However, there is a stark difference in the functional attributes of $\mathrm{NK}$ cells present in the CSF compared to those in the peripheral blood (55). These cells cannot enter the brain through the BBB (51). This partly explains why levels of NK cells in PD patients were significantly higher than those in healthy controls. Deviation from reference values increases the risk of PD, but that is not related to clinical features, especially motor symptoms.

Although we did not find a difference between PD patients and healthy controls in the percentage of $\mathrm{B}$ cells, their deviation from reference values also led to an increased risk of PD. Xiao et al. found defects in B cell-mediated immune responses in $\alpha-$ syn $^{-/-}$mice (56). Mice deficient in $\mathrm{T}$ and $\mathrm{B}$ lymphocytes were resistant to MPTP-induced neurodegeneration (57). This result indicates that $\mathrm{B}$ lymphocytes could also contribute to the progression of $\mathrm{PD}$.

The BBB is a key player that physically separates the peripheral immune system from the brain. BBB disruption has been reported in PD patients (58-60). Only a specific number of activated $\mathrm{T}$ cells are allowed to get through the BBB and BCSFB to the brain (51). This finding partially explained that the dysfunction of $\mathrm{T}$ cell profiles had a close relationship with clinical manifestations in PD patients $(61,62)$.

Our study found an obvious decrease of circulating $\mathrm{CD}^{+}$ $\mathrm{T}$ cells in PD patients compared to healthy controls, and people with $\mathrm{CD}^{+} \mathrm{T}$ cells deviating from the reference range had an increased risk of PD. However, multivariate analysis did not reveal any consistent relationships between $\mathrm{CD}^{+} \mathrm{T}$ cells and clinical feathers. $\mathrm{CD}^{+} \mathrm{T}$ cells, can acquire proinflammatory and anti-inflammatory phenotypes corresponding to different inflammatory states (52). A complex phenotypic and functional Th1 bias has already been described in the peripheral immune system in PD patients (63). Kustrimovic et al. found that PD patients have reduced circulating $\mathrm{CD}^{+} \mathrm{T}$ lymphocytes, due to reduced Th2, Th17, and Treg (63). Howard E. Gendelman et al. found that changes in $\mathrm{CD}^{+}{ }^{+} \mathrm{T}$ cell, Treg and Teff phenotypes were associated with motor function scores determined by UPDRS-III score (64). In addition, an extensive association between DR expression in $\mathrm{CD}^{+} \mathrm{T}$ cells and motor dysfunction, as assessed by the UPDRS 
Part III score has been reported in PD patients. DRD1 and DRD5 expression negatively correlated with the UPDRS III score in $\mathrm{CD}^{+}{ }^{+} \mathrm{T}$ naive cells, on the contrary, DRD2 and DRD4 receptor increased with the UPDRS III score in both $\mathrm{CD}^{+}$central memory $\mathrm{T}(\mathrm{TCM})$ and effector memory $\mathrm{T}$ (TEM) cells (15). DRD3 expression is reduced in $\mathrm{CD}^{+}$ $\mathrm{T}$ cells from PD patients and its pharmacologic inhibition attenuates the motor impairment in MPTP-treated mice (65). These studies indicated that the correlation between $\mathrm{CD}^{+} \mathrm{T}$ cells and motor dysfunctions depends on the phenotype and DR expression, although $\mathrm{CD}^{+} \mathrm{T}$ cells mediate the cytotoxic effect on dopaminergic neurons (8).

Interestingly, we found that patients who had $\mathrm{CD} 8^{+} \mathrm{T}$ cells deviating from the reference range had significantly higher MDS-UPDRS-III scores than patients with normal indicators, even though no obvious difference in $\mathrm{CD}^{+} \mathrm{T}$ cells was detected between PD and control groups. Through a multivariable linear regression model adjusted for gender, age and LEDD, we found that deviation from the reference range of $\mathrm{CD}^{+} \mathrm{T}$ cells was positively associated with MDSUPDRS-III score. Peripheral CD $8^{+} \mathrm{T}$ cells may migrate and accumulate in the brains of PD patients $(8,61)$. In the MPTP model, infiltrating $T$ cells predominantly consisted of $\mathrm{CD}^{+} \mathrm{T}$ cells, although $\mathrm{CD} 4^{+} \mathrm{T}$ cells were also present $(8,66)$. In addition, $\alpha$-syn has been shown to have a robust capacity to trigger the $\mathrm{T}$ cell response in the brain (67). Major histocompatibility complex I (MHC-I) expression renders catecholaminergic neurons susceptible to T-cellmediated degeneration (68). $\mathrm{CD}^{+} \mathrm{T}$ cells could recognize $\alpha$-syn peptides and bind the antigens presented by MHC class I molecules in dopamine neurons to proceed with Fas and perforin-based cytotoxic T lymphocyte (CTL) apoptosis (69). Decreased numbers of dopamine neurons are related to motor symptoms, which could be assessed by the UPDRS-III score. That may explain part of the correlation between alternations of peripheral blood $\mathrm{CD} 8^{+}$ $\mathrm{T}$ cell and motor dysfunction.

The main limitations of our study are that: (I) no $\mathrm{CD} 4^{+}$ T cells subtype classification was performed, and surface DR expression were not detected yet. (II) There was no detection of peripheral blood $\alpha$-syn levels. These factors might be more conducive for explaining the mechanism of peripheral blood changes. A more comprehensive design should be carried out in subsequent studies. The phenomenon of peripheral blood lymphocytes deviating from the reference range in PD deserves more attention and exploration in people from different regions and different racial backgrounds, and in patients with other neurodegenerative diseases.

\section{Conclusions}

We conclude that the phenomenon of peripheral blood lymphocytes that deviate from the reference range could be a meaningful indicator for PD. Altered peripheral blood lymphocyte subpopulations have clinical relevance for PD.

\section{Acknowledgments}

Funding: This work was supported by research grants from the National Key R\&D Program of China (No. 2016YFC1306601), Natural Science Foundation of Shandong Province, China (No. BS2015YY041), and Technology Project of Guangzhou, China (No. 2018-1202SF-0019).

\section{Footnote}

Conflicts of Interest: The authors have no conflicts of interest to declare.

Ethical Statement: The authors are accountable for all aspects of the work in ensuring that questions related to the accuracy or integrity of any part of the work are appropriately investigated and resolved. Each participant signed their informed consent before the trial. The procedures were approved by the Ethics Committee of Qilu Hospital of Shandong University [No. KYLL2017(KS)-270].

\section{References}

1. Emamzadeh FN, Surguchov A. Parkinson's Disease: Biomarkers, Treatment, and Risk Factors. Front Neurosci 2018;12:612.

2. Klingelhoefer L, Reichmann H. Pathogenesis of Parkinson disease--the gut-brain axis and environmental factors. Nat Rev Neurol 2015;11:625-36.

3. Brundin P, Melki R. Prying into the Prion Hypothesis for Parkinson's Disease. J Neurosci 2017;37:9808-18.

4. Harms AS, Delic V, Thome AD, et al. $\alpha$-Synuclein fibrils recruit peripheral immune cells in the rat brain prior to neurodegeneration. Acta Neuropathol Commun 2017;5:85.

5. Gelders G, Baekelandt V, Van der Perren A. Linking Neuroinflammation and Neurodegeneration in Parkinson's 
Disease. J Immunol Res 2018;2018:4784268.

6. Sulzer D, Alcalay RN, Garretti F, et al. T cells from patients with Parkinson's disease recognize $\alpha$ - synuclein peptides. Nature 2017;546:656-61.

7. McGeer PL, Itagaki S, McGeer EG. Expression of the histocompatibility glycoprotein HLA-DR in neurological disease. Acta Neuropathol 1988;76:550-7.

8. Brochard V, Combadière $\mathrm{B}$, Prigent $\mathrm{A}$, et al. Infiltration of $\mathrm{CD} 4+$ lymphocytes into the brain contributes to neurodegeneration in a mouse model of Parkinson disease. J Clin Invest 2009;119:182-92.

9. Sui YT, Bullock KM, Erickson MA, et al. Alpha synuclein is transported into and out of the brain by the blood-brain barrier. Peptides 2014;62:197-202.

10. Allen Reish HE, Standaert DG. Role of $\alpha$-synuclein in inducing innate and adaptive immunity in Parkinson disease. J Parkinsons Dis 2015;5:1-19.

11. Chiba S, Matsumoto H, Saitoh M, et al. A correlation study between serum adenosine deaminase activities and peripheral lymphocyte subsets in Parkinson's disease. J Neurol Sci 1995;132:170-3.

12. Baba Y, Kuroiwa A, Uitti RJ, et al. Alterations of T-lymphocyte populations in Parkinson disease. Parkinsonism Relat Disord 2005;11:493-8.

13. Caggiu E, Paulus K, Galleri G, et al. Homologous HSV1 and alpha-synuclein peptides stimulate a $\mathrm{T}$ cell response in Parkinson's disease. J Neuroimmunol 2017;310:26-31.

14. Chen Y, Qi B, Xu W, Ma B, et al. Clinical correlation of peripheral CD4+-cell sub-sets, their imbalance and Parkinson's disease. Mol Med Rep 2015;12:6105-11.

15. Kustrimovic N, Rasini E, Legnaro M, et al. Dopaminergic Receptors on CD4+ T Naive and Memory Lymphocytes Correlate with Motor Impairment in Patients with Parkinson's Disease. Sci Rep 2016;6:33738.

16. Niwa F, Kuriyama N, Nakagawa M, et al. Effects of peripheral lymphocyte subpopulations and the clinical correlation with Parkinson's disease. Geriatr Gerontol Int 2012;12:102-7.

17. Marttila RJ, Eskola J, Soppi E, et al. Immune functions in Parkinson's disease lymphocyte subsets, concanavalin A-induced suppressor cell activity and in vitro immunoglobulin production. J Neurol Sci 1985;69:121-31.

18. Gruden MA, Sewell RD, Yanamandra K, et al. Immunoprotection against toxic biomarkers is retained during Parkinson's disease progression. J Neuroimmunol 2011;233:221-7. Erratum in: J Neuroimmunol 2014;268:99. Bocharova, Olga R [corrected to Bocharova, Olga A].
19. Hurny A, Michałowska-Wender G, Wender M. Impact of L-DOPA treatment of patients with Parkinson's disease on mononuclear subsets and phagocytosis in the peripheral blood. Folia Neuropathol 2013;51:127-31.

20. Hisanaga K, Asagi M, Itoyama $Y$, et al. Increase in peripheral CD4 bright+ CD8 dull+ T cells in Parkinson disease. Arch Neurol 2001;58:1580-3.

21. Mihara T, Nakashima M, Kuroiwa A, et al. Natural killer cells of Parkinson's disease patients are set up for activation: a possible role for innate immunity in the pathogenesis of this disease. Parkinsonism Relat Disord 2008;14:46-51.

22. Bas J, Calopa M, Mestre M, et al. Lymphocyte populations in Parkinson's disease and in rat models of parkinsonism. J Neuroimmunol 2001;113:146-52.

23. Schröder JB, Pawlowski M, Meyer Zu Hörste G, et al. Immune Cell Activation in the Cerebrospinal Fluid of Patients With Parkinson's Disease. Front Neurol 2018;9:1081.

24. Rocha NP, Assis F, Scalzo PL, et al. Reduced Activated T Lymphocytes (CD4+CD25+) and Plasma Levels of Cytokines in Parkinson's Disease. Mol Neurobiol 2018;55:1488-97.

25. Perner C, Perner F, Gaur N, et al. Plasma VCAM1 levels correlate with disease severity in Parkinson's disease. J Neuroinflammation 2019;16:94.

26. Cen L, Yang C, Huang S, et al. Peripheral Lymphocyte Subsets as a Marker of Parkinson's Disease in a Chinese Population. Neurosci Bull 2017;33:493-500.

27. Zhang S, Sun C, Zhang L, et al. Clinical analysis of subpopulation of peripheral $\mathrm{T}$ and $\mathrm{B}$ lymphocytes in Chinese Parkinson's disease patients. Zhonghua Yi Xue Za Zhi 2014;94:3726-30.

28. Tan F, Gu W, Huang T, et al. Changes and its clinical significance of natural kill cell and $\mathrm{T}$ lymphocyte subsets in Parkinson disease patients. Chinese Journal of Immunology 2003;19:138-40.

29. Li F, Zhang P, Cao C, et al. Analysis of T lymphocyte subsets in peripheral blood from patients with Parkinson's disease. Journal of Tianjin Medical University 2012;18:208-11.

30. Gao P, Qian C, Liu X, et al. Clinical study of T lymphocyte and natural kill cell with Parkinson disease. Journal of Clinical Medicine in Practice 2005;9:52-4.

31. Lei G, Miao J, Li Z. T Lymphocyte subgroups and erythrocyte immune function in Parkinson disease patients. Chinese Journal of Neuroimmunology and Neurology 2001;8:95-7. 
32. Yu NW, Liu J, Li X, et al. Changes of T lymphocyte subgroups in peripheral blood of Parkionson's disease patients. Sichuan Medical Journal 2012;33:1487-90.

33. Xu Z, Rui Qiao R, Jiang S, et al. Analysis of immune related cells in peripheral blood of patients with Parkinson's disease. Journal of Shanxi Medical University 2019;50:329-32.

34. Stevens CH, Rowe D, Morel-Kopp MC, et al. Reduced T helper and B lymphocytes in Parkinson's disease. J Neuroimmunol 2012;252:95-9.

35. Tribl GG, Wöber C, Schönborn V, et al. Amantadine in Parkinson's disease: lymphocyte subsets and IL-2 secreting $T$ cell precursor frequencies. Exp Gerontol 2001;36:1761-71.

36. Postuma RB, Berg D, Stern M, et al. MDS clinical diagnostic criteria for Parkinson's disease. Mov. Disord 2015;30:1591-601.

37. Chng WJ, Tan GB, Kuperan P. Establishment of adult peripheral blood lymphocyte subset reference range for an Asian population by single-platform flow cytometry: influence of age, sex, and race and comparison with other published studies. Clin Diagn Lab Immunol 2004; 11:168-73.

38. Collier TJ, Kanaan NM, Kordower JH. Aging and Parkinson's disease: Different sides of the same coin? Mov Disord 2017;32:983-90.

39. Qin L, Jing X, Qiu Z, et al. Aging of immune system: Immune signature from peripheral blood lymphocyte subsets in 1068 healthy adults. Aging (Albany NY) 2016;8:848-59.

40. Jiang S, Gao H, Luo Q, et al. The correlation of lymphocyte subsets, natural killer cell, and Parkinson's disease: a meta-analysis. Neurol Sci 2017;38:1373-80.

41. Choong ML, Ton SH, Cheong SK. Influence of race, age and sex on the lymphocyte subsets in peripheral blood of healthy Malaysian adults. Ann Clin Biochem 1995;32:532-9.

42. Zhang K, Wang F, Zhang M, et al. Reference ranges of lymphocyte subsets balanced for age and gender from a population of healthy adults in Chongqing District of China. Cytometry B Clin Cytom 2016;90:538-42.

43. Huang $\mathrm{C}, \mathrm{Li} \mathrm{W}, \mathrm{Wu} \mathrm{W}$, et al. Intra-day and inter-day biological variations of peripheral blood lymphocytes. Clin Chim Acta 2015;438:166-70.

44. Zhang Y, Wen H, Zhang ZX, et al. Reference values of blood lymphocyte immunophenotype in the normal healthy adults of Ugyur and Han nationalities in Xinjiang. Zhongguo Shi Yan Xue Ye Xue Za Zhi 2006;14:133-6.

45. Wang C, Dou C, Wang T, et al. Investigation on the peripheral blood lymphocyte subsets among healthy adults in Jining area. Hainan Medical Journal 2018;29:3263-7.

46. Surgucheva I, Newell KL, Burns J, et al. New $\alpha$ - and $\gamma$-synuclein immunopathological lesions in human brain. Acta Neuropathol Commun 2014;2:132.

47. Kim S, Jeon BS, Heo C, et al. Alpha-synuclein induces apoptosis by altered expression in human peripheral lymphocyte in Parkinson's disease. FASEB J 2004;18:1615-7.

48. McKenna F, McLaughlin PJ, Lewis BJ, et al. Dopamine receptor expression on human $\mathrm{T}$ - and B-lymphocytes, monocytes, neutrophils, eosinophils and NK cells: a flow cytometric study. J Neuroimmunol 2002;132:34-40.

49. Mackie P, Lebowitz J, Saadatpour L, et al. The dopamine transporter: An unrecognized nexus for dysfunctional peripheral immunity and signaling in Parkinson's Disease. Brain Behav Immun 2018;70:21-35.

50. Levite M. Dopamine and T cells: dopamine receptors and potent effects on $\mathrm{T}$ cells, dopamine production in $\mathrm{T}$ cells, and abnormalities in the dopaminergic system in $\mathrm{T}$ cells in autoimmune, neurological and psychiatric diseases. Acta Physiol (Oxf) 2016;216:42-89.

51. Negi N, Das BK. CNS: Not an immunoprivilaged site anymore but a virtual secondary lymphoid organ. Int Rev Immunol 2018;37:57-68.

52. Fuzzati-Armentero MT, Cerri S, Blandini F. PeripheralCentral Neuroimmune Crosstalk in Parkinson's Disease: What Do Patients and Animal Models Tell Us? Front Neurol 2019;10:232.

53. Tsay GJ, Zouali M. The Interplay Between Innate-Like B Cells and Other Cell Types in Autoimmunity. Front Immunol 2018;9:1064.

54. Dobbs SM, Dobbs RJ, Weller C, et al. Peripheral aetiopathogenic drivers and mediators of Parkinson's disease and co-morbidities: role of gastrointestinal microbiota. J Neurovirol 2016;22:22-32.

55. Han S, Lin YC, Wu T, et al. Comprehensive immunophenotyping of cerebrospinal fluid cells in patients with neuroimmunological diseases. J Immunol 2014;192:2551-63.

56. Xiao W, Shameli A, Harding CV, et al. Late stages of hematopoiesis and $\mathrm{B}$ cell lymphopoiesis are regulated by $\alpha$-synuclein, a key player in Parkinson's disease. Immunobiology 2014;219:836-44.

57. Benner EJ, Banerjee R, Reynolds AD, et al. Nitrated alpha-synuclein immunity accelerates degeneration of nigral dopaminergic neurons. PLoS One 2008;3:e1376.

58. Kortekaas R, Leenders KL, van Oostrom JC, et al. Blood- 
brain barrier dysfunction in parkinsonian midbrain in vivo. Ann Neurol 2005;57:176-9.

59. Bartels AL, Willemsen AT, Kortekaas R, et al. Decreased blood-brain barrier P-glycoprotein function in the progression of Parkinson's disease, PSP and MSA. J Neural Transm (Vienna) 2008;115:1001-9.

60. Erdő F, Denes L, de Lange E. Age-associated physiological and pathological changes at the blood-brain barrier: A review. J Cereb Blood Flow Metab 2017;37:4-24.

61. Chen Z, Chen S, Liu J. The role of T cells in the pathogenesis of Parkinson's disease. Prog Neurobiol 2018;169:1-23.

62. Baird JK, Bourdette D, Meshul CK, et al. The key role of T cells in Parkinson's disease pathogenesis and therapy. Parkinsonism Relat Disord 2019;60:25-31.

63. Kustrimovic N, Comi C, Magistrelli L, et al. Parkinson's disease patients have a complex phenotypic and functional Th1 bias: cross-sectional studies of CD4+ Th1/Th2/ T17 and Treg in drug-naïve and drug-treated patients. J Neuroinflammation 2018;15:205.

64. Saunders JA, Estes KA, Kosloski LM, et al. CD4+ regulatory and effector/memory $T$ cell subsets profile motor dysfunction in Parkinson's disease. J Neuroimmune
Pharmacol 2012;7:927-38.

65. Elgueta D, Contreras F, Prado C, et al. Dopamine Receptor D3 Expression Is Altered in CD4+ T-Cells From Parkinson's Disease Patients and Its Pharmacologic Inhibition Attenuates the Motor Impairment in a Mouse Model. Front Immunol 2019;10:981.

66. Kurkowska-Jastrzebska I, Wrońska A, Kohutnicka M, et al. MHC class II positive microglia and lymphocytic infiltration are present in the substantia nigra and striatum in mouse model of Parkinson's disease. Acta Neurobiol Exp (Wars) 1999;59:1-8.

67. Thakur P, Breger LS, Lundblad M, et al. Modeling Parkinson's disease pathology by combination of fibril seeds and $\alpha$-synuclein overexpression in the rat brain. Proc Natl Acad Sci U S A 2017;114:E8284-93.

68. Cebrián C, Zucca FA, Mauri P, et al. MHC-I expression renders catecholaminergic neurons susceptible to $\mathrm{T}$-cellmediated degeneration. Nat Commun 2014;5:3633.

69. Coque E, Salsac C, Espinosa-Carrasco G, et al. Cytotoxic CD8+ T lymphocytes expressing ALS-causing SOD1 mutant selectively trigger death of spinal motoneurons. Proc Natl Acad Sci U S A 2019;116:2312-7.

Cite this article as: Sun C, Zhao Z, Yu W, Mo M, Song C, Si Y, Liu Y. Abnormal subpopulations of peripheral blood lymphocytes are involved in Parkinson's disease. Ann Transl Med 2019;7(22):637. doi: 10.21037/atm.2019.10.105 